\title{
Research Article \\ Construction of a New Sensor with Copper(II) Complex Anchored in Calcium Phosphate Intercalated with m-Aminobenzoic Acid and Their Application in Determination of Dopamine
}

\author{
Angélica M. Lazarin, Marco A. G. Benetti, Denise I. Soares, Giovanna G. Alves, and Eduardo D. A. Pinto \\ Departamento de Química, Universidade Estadual de Maringá, Av. Colombo, 5790, 87020-900 Maringá, PR, Brazil \\ Address correspondence to Angélica M. Lazarin,amlazarin2@uem.br
}

Received 18 November 2021; Revised 18 January 2022; Accepted 20 January 2022

Copyright (C) 2022 Angélica M. Lazarin et al. This is an open access article distributed under the terms of the Creative Commons Attribution License, which permits unrestricted use, distribution, and reproduction in any medium, provided the original work is properly cited.

\begin{abstract}
Crystalline lamellar calcium phosphate retained $\mathrm{m}$ aminobenzoic acid inside its cavity without leaching. The intense infrared bands in the $1,033 \mathrm{~cm}^{-1}$ and $1,010 \mathrm{~cm}^{-1}$ intervals confirmed the presence of the phosphate groups attached to the inorganic layer, with sharp and intense peaks in X-ray diffraction patterns, which gave basal distances of $535 \mathrm{pm}$ and $947 \mathrm{pm}$ for the original and the intercalated compounds, respectively. The adsorption isotherm of copper(II) on a calcium phosphate host intercalated with $\mathrm{m}$ aminobenzoic acid was studied in ethanol solution to give a maximum adsorption capacity of $1.43 \mathrm{mmoL} \mathrm{g}^{-1}$. The material was incorporated into carbon paste electrode and its electrochemical properties were investigated. However, for a dopamine solution, an enhancement of the anodic peak current was detected due to the electrocatalytic oxidation. The electrode presented the same response for at least 150 successive measurements, with a good repeatability. The modified electrode is very stable and reproducible. The sensor was applied for dopamine determination in pharmaceutical preparation (one commercial sample (Revivan)) with success
\end{abstract}

Keywords calcium phosphate; intercalation; cyclic voltammetry; electrocatalytic oxidation; copper(II); dopamine

\section{Introduction}

Phosphates intercalated with organic compounds have aroused interest, since they can act as binders for the coordination of metal ions on their surface and be used in the construction of chemically modified electrodes (CMEs), together with a carbon paste electrode (CPE), in the study of the electrochemical behavior of these compounds, in electroanalysis, and in electrocatalysis $[1,2,3,4,5,6,7,8]$.

The use of cyclic voltammetry and/or differential pulse voltammetry, with modified chemically electrodes as the working electrode, shall be an efficient and very sensitive analytical method for studying the electrocatalytic oxidation of reagents of biological interest, such as ascorbic acid (AA), dopamine (DA), and vitamin $\mathrm{B}_{6}[9,10]$.

The present investigation deals with the electrochemical behavior of copper(II) adsorbed on calcium phosphate intercalated with m-aminobenzoic acid. This newly synthesized compound was first used to prepare a CPE and the resulting material was tested for DA oxidation. DA (3,4-dihydroxyphenylethylamine) is a catecholamine of great clinical and pharmaceutical interest, which acts as a chemical mediator in central nervous, cardiovascular, and hormonal systems; its concentration in extracellular fluid is lower than the AA present. DA deficiency in central nervous system causes serious diseases like Parkinson and Schizophrenia [11]. Therefore, its determination in vitro and in vivo has attracted a lot of attention $[12,13]$. The greatest interest in development of these voltammetric sensors is the advantage to be used in a living organism to detect neurotransmitters in extracellular fluid of central nervous system with the detection of DA in the presence of high concentration of AA, which is oxidized at the same potential of DA in unmodified electrodes [14, 15]. An electrochemical procedure, using an innovative, stable innovator inorganic support, is now proposed.

\section{Experimental}

\subsection{Synthesis of calcium phosphate}

Calcium phosphate was synthesized by slowly adding a $0.50 \mathrm{~mol} \mathrm{dm}^{-3}$ aqueous solution of $\mathrm{CaCl}_{2} \cdot 2 \mathrm{H}_{2} \mathrm{O}$ to a $1.50 \mathrm{~mol} \mathrm{dm}^{-3}$ solution of dibasic ammonium phosphate and heated to $363 \mathrm{~K}$. The suspension formed remained reacting for $1 \mathrm{~h}$ and then the precipitate formed was filtered and dried at $323 \mathrm{~K}$. Then this compound was heated to $433 \mathrm{~K}$, for $48 \mathrm{~h}$, to eliminate ammonia, whose reactions can be written as

$$
\begin{aligned}
& \mathrm{CaCl}_{2} \cdot 2 \mathrm{H}_{2} \mathrm{O}+2\left(\mathrm{NH}_{4}\right)_{2} \mathrm{HPO}_{4} \\
& \quad \longrightarrow\left(\mathrm{NH}_{4}\right)_{2} \mathrm{Ca}\left(\mathrm{HPO}_{4}\right)_{2} \cdot \mathrm{H}_{2} \mathrm{O}+2 \mathrm{NH}_{4} \mathrm{Cl}+\mathrm{H}_{2} \mathrm{O} \\
& \left(\mathrm{NH}_{4}\right)_{2} \mathrm{Ca}\left(\mathrm{HPO}_{4}\right)_{2} \cdot \mathrm{H}_{2} \mathrm{O} \\
& \quad \longrightarrow \mathrm{Ca}\left(\mathrm{H}_{2} \mathrm{PO}_{4}\right)_{2}+2 \mathrm{NH}_{3}+\mathrm{H}_{2} \mathrm{O}
\end{aligned}
$$




\subsection{Intercalation procedure}

Approximately, $5.0 \mathrm{~g}$ of calcium phosphate in a conical flask with $10.0 \mathrm{~cm}^{3}$ of $1.0 \mathrm{~mol} \mathrm{dm}^{-3}$ ethanolic solution of $\mathrm{m}$-aminobenzoic acid were stirred in a thermostated bath at $298 \pm 1 \mathrm{~K}$ and $308 \pm 1 \mathrm{~K}$ for $12 \mathrm{~h}$. The supernatant was discarded and the solid was oven dried at $323 \mathrm{~K}$. This material was used to construct a CME.

\subsection{Characterization}

For the elemental analysis of calcium and phosphorus, samples in triplicates of approximately $50 \mathrm{mg}$ of calcium phosphate were placed in ostefron decomposition flasks for microwaves with a capacity of $100 \mathrm{~cm}^{3}$, for acid digestion, in the presence of $2.0 \mathrm{~cm}^{3}$ of nitric acid $(65 \%), 2.0 \mathrm{~cm}^{3}$ of hydrofluoric acid $(48 \%)$, and $1.0 \mathrm{~cm}^{3}$ of hydrogen peroxide $(30 \%)$. Then these samples were taken to a Provecto analytical microwave oven, model DGT 100 plus, for mineralization of the compounds. The total time used was $18 \mathrm{~min}$. Then waiting about $1 \mathrm{~h}$ to open the ostefron decomposition vials, shortly thereafter the hydrofluoric acid was eliminated from the samples in the presence of approximately $2 \mathrm{~g}$ of boric acid. Three samples of each compound were diluted in $250 \mathrm{~cm}^{3}$ flask and subsequently analyzed. Each sample was measured three times using PerkinElmer Optima 3000 DV inductively coupled plasma (ICP-AES), as it has good multi-element detection sensitivity and minimal interference in the analyzed sample. The precision between replicates was less than $5 \%$ [16].

The amount of m-aminobenzoic acid intercalated into calcium phosphate was determined by nitrogen elemental analysis on a PerkinElmer 2400 Series II CHNS/O Elemental Analyzer.

X-ray diffraction patterns were obtained with nickelfiltered $\operatorname{CuK} \alpha(0.154 \mathrm{~nm})$ radiation in the interval of $2^{\circ}$ to $65^{\circ}$ at a speed of $0.033^{\circ} \mathrm{s}^{-1}$ and a step of $0.050^{\circ}$ on a Shimadzu XD3-A diffractometer $(30 / 20 \mathrm{kV} / \mathrm{mA})$.

Infrared spectra of the samples were performed on a PerkinElmer FTIR spectrophotometer, model 1600, by using pressed $\mathrm{KBr}$ pellets in the $4,000-400 \mathrm{~cm}^{-1}$ range with $4 \mathrm{~cm}^{-1}$ of resolution.

The surface area measurements were performed on a Micromeritics FlowSorb 2300 instrument through gaseous nitrogen adsorption at $77 \mathrm{~K}$, by applying the BET method [17].

\subsection{Adsorption isotherms}

Using the batchwise method, the adsorption isotherm for $\mathrm{CuCl}_{2}$ in ethanol solution was obtained. For each isotherm, a series of samples containing $100 \mathrm{mg}$ of $\mathrm{CaP}$ intercalated with m-aminobenzoic acid was shaken for $4 \mathrm{~h}$, as previously established [18], in an orbital bath with variable concentrations of the metal halide at a constant temperature of $298 \pm 1 \mathrm{~K}$. At different time intervals, an aliquot of the supernatant solution was separated and the metal ion was analyzed by complexiometric titration using EDTA as the titrant [19]. The amount of copper(II) adsorbed, $n_{f}$, was determined by applying the equation $n_{f}=\left(n_{i}-n_{s}\right) / m$, where $m$ is the mass of the adsorbent and $n_{i}$ and $n_{s}$ are the initial and the equilibrium amounts of the number of moles of copper cations in the solution phase, respectively. The isotherms used here are those related to the Langmuir model, which was originally derived for gas adsorption on planar surfaces such as glass, mica, and platinum. The process was successfully extended to heavy metal ion adsorptions on porous surfaces [20].

\subsection{Electrochemical measurements}

The modified CPE was prepared by mixing $30 \mathrm{mg}$ of the intercalated-adsorbed copper(II) calcium phosphate, $30 \mathrm{mg}$ of graphite (Fluka), and a drop of mineral oil $\left(2.0 \times 10^{-2} \mathrm{~cm}^{3}\right)$. The paste was deposited into a cavity on the surface of a platinum disk fused at the end of a glass tube with $3 \mathrm{~mm}$ inner diameter. This proportion was used due to a good response obtained with a preliminary test, after a detailed study of the paste composition. This electrode is referred hereafter as $\mathrm{CaP} / \mathrm{MABA} / \mathrm{Cu}(\mathrm{II})$.

Electrochemical measurements were performed using this $\mathrm{CPE}$ as the working electrode, saturated calomel electrode (SCE) as reference electrode, and a platinum wire as auxiliary electrode. The electrochemical copper(II) properties adsorbed on calcium phosphate intercalated with m-aminobenzoic acid were explored by means of cyclic voltammetry with a PAR 273A (EG\&G) potentiostatgalvanostat. Experiments were performed in $0.10 \mathrm{~mol} \mathrm{dm}^{-3}$ of phosphate buffer electrolyte solution under a pure nitrogen atmosphere and $\mathrm{pH}=7.2$ were adjusted by adding hydrochloric acid or sodium hydroxide solutions. The DA (Aldrich) was used in all experiments. The determination of DA in commercial samples (Revivan) consisted in dissolving $2.0 \mathrm{~cm}^{3}$ of Revivan in doubly distilled, degassed water and completed to $10.0 \mathrm{~cm}^{3}$.

\section{Results and discussion}

\subsection{Characterizations}

The elemental analyses of calcium and phosphorus for the synthesized calcium phosphate compound were $26.3 \%$ and $17.2 \%$, respectively. These values are very close to those calculated $26.5 \%$ and $17.1 \%$. From these results, the molecular formula $\mathrm{Ca}\left(\mathrm{H}_{2} \mathrm{PO}_{4}\right)_{2}$ was proposed.

The amount of m-aminobenzoic acid intercalated in calcium phosphate at $298 \pm 1 \mathrm{~K}$ was $9.07 \%$ nitrogen atoms, which corresponds to $6.48 \mathrm{mmoL} \mathrm{g}^{-1}$. And at a temperature of $308 \pm 1 \mathrm{~K}$ it was $9.08 \%$ nitrogen atoms, which corresponds to $6.49 \mathrm{mmoL} \mathrm{g}^{-1}$. Therefore, in the intercalation process there was no influence of temperature. 


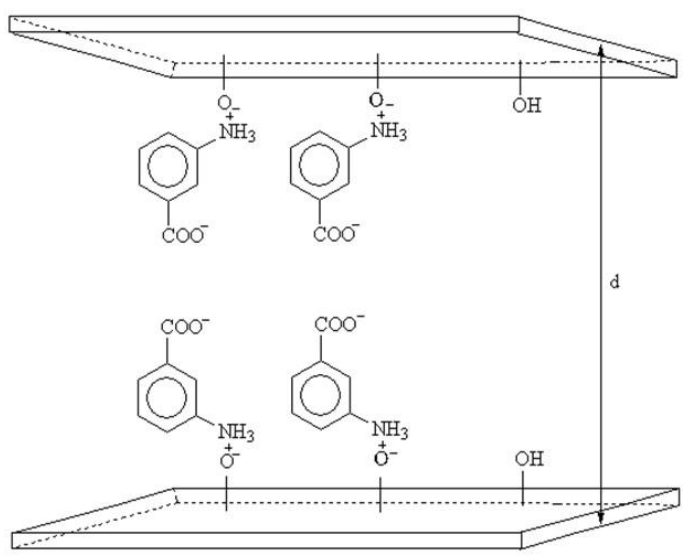

Figure 1: Representative scheme of a possible way of intercalation of MABA with the hydroxylated surface of CaP.

The proposed chemical structure of the crystalline $\mathrm{CaP}$ interlayer is indicated in Figure 1.

The layered structural feature of the crystalline calcium phosphate displays an interlayer distance which depends on cation size or molecule intercalated into the host. Thus Xray powder diffractogram is a good tool for observing the change in interlayer distance, in order to follow the uptake process.

X-ray diffractogram provides the angle between incident and diffracted rays in the sample $(2 \theta)$, showing relative intensity. The technique is not destructive and only small amounts of the powder sample are adequate to identify the crystalline phase present. Through the Bragg equation,

$n \lambda=2 d \sin \theta$,

where $\lambda=1.5406 \AA$ the wavelength of the radiation used, it can be determined by the interlamellar distance $d(\AA)$ between atomic planes of the crystalline network.

$\mathrm{X}$-ray diffractograms of calcium phosphate and its form intercalated with $\mathrm{m}$-aminobenzoic acid are shown in Figure 2. Calcium phosphate shows fine peaks indicating good crystallinity. The peak at $2 \theta=16.73^{\circ}$, relative to the first reflection related to the plane (002), informs that the interlayer distance of calcium phosphate is equal to $535 \mathrm{pm}$ [21]. Interlayer distance increases to $947 \mathrm{pm}$ when calcium phosphate is intercalated with m-aminobenzoic acid. An increase of $412 \mathrm{pm}$ compared to the original matrix shows that the intercalation occurs on the inner surface of the inorganic support (Figure 1).

FT-IR spectra of calcium phosphate and its form intercalated with m-aminobenzoic acid are shown in Figure 3. The results show band stretching and deformation at $3,400 \mathrm{~cm}^{-1}$ and $1,550 \mathrm{~cm}^{-1}$, which is due to the $\mathrm{OH}$ group of the phosphate. Characteristic bands of the phosphate groups appear in $1,033 \mathrm{~cm}^{-1}$ and $1,010 \mathrm{~cm}^{-1}$ [22]. In a calcium phosphate spectrum intercalated with $\mathrm{m}$-aminobenzoic acid

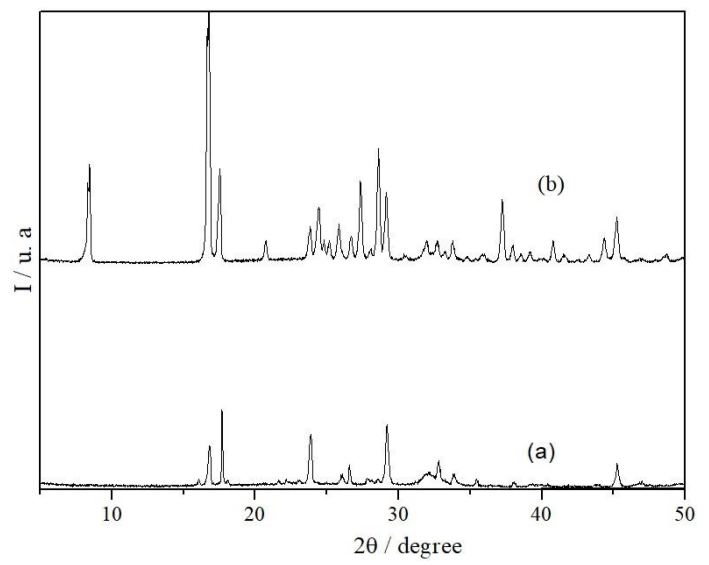

Figure 2: X-ray diffraction patterns of calcium phosphate (a) and its form intercalated (b) with m-aminobenzoic acid.

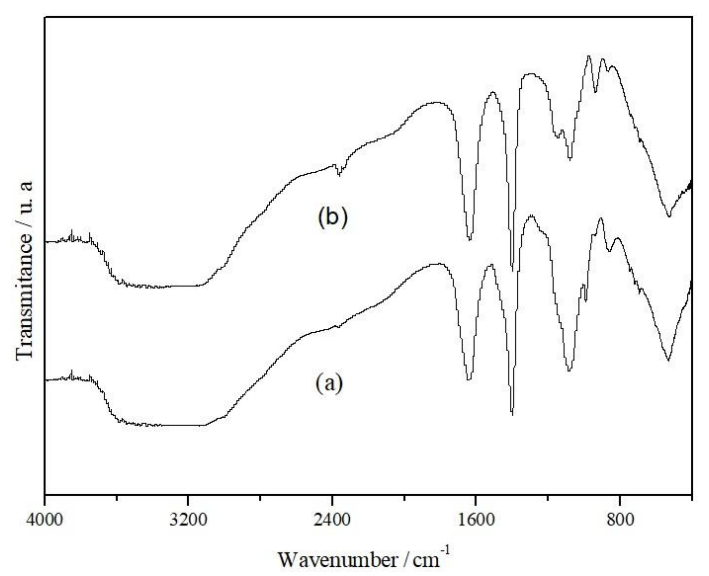

Figure 3: Infrared spectrum of calcium phosphate (a) and its form intercalated with $\mathrm{m}$-aminobenzoic acid (b).

(Figure 3(b)), it is not possible to verify the presence of bands attributed to vibrations of $\mathrm{NH}$ group $\left(3,400 \mathrm{~cm}^{-1}\right.$ to $3,300 \mathrm{~cm}^{-1}$ ) and other bands of inorganic matrix suffered little change with intercalation.

The area of calcium phosphate compound was equal to $20.5 \pm 0.3 \mathrm{~m}^{2} \mathrm{~g}^{-1}$ with interlayer distance of $535 \mathrm{pm}$. When this compound is intercalated with $\mathrm{m}$-aminobenzoic acid, it is observed that the area increases to $21.6 \pm 0.5 \mathrm{~m}^{2} \mathrm{~g}^{-1}$. This fact may be due to amines accommodation within the interlayer region.

\subsection{Adsorption of copper}

Taking into account a property associated with the intercalated crystalline lamellar compound for adsorbing metal ions from ethanol solution, the corresponding isotherm for selected cations was investigated, copper(II). Initially, investigation demonstrated that the original matrix, without MABA, does not adsorb this cation. Adsorption 


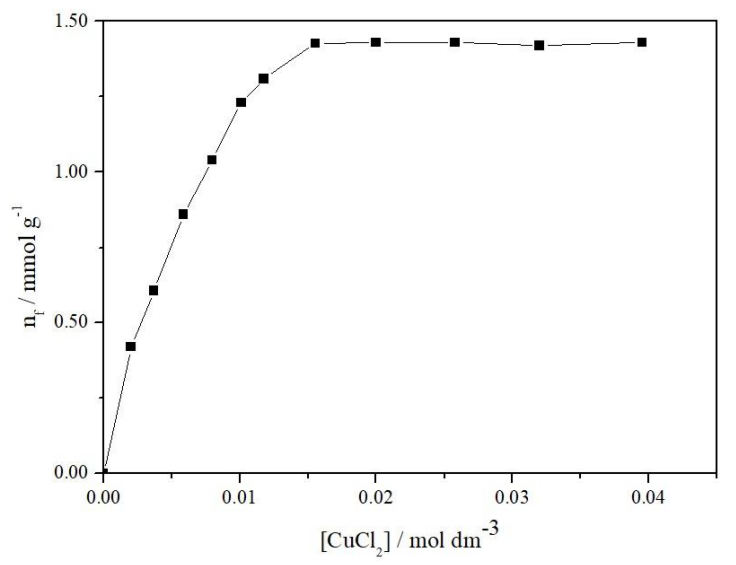

Figure 4: Isotherm of copper(II) complexation on the maminobenzoic acid in $\mathrm{CaP}$ compound.

isotherm of CaP/MABA system is shown in Figure 4. The amount of copper cation on the host surface is given by $1.43 \mathrm{mmoL}$ per gram of the solid.

\subsection{Electrochemical studies}

After preparation of CMEs, cyclic voltammograms were obtained, in the potential range of $-1.0-1.0 \mathrm{~V}$, under argon. For CaP/MABA modified electrode, no peak current was observed, however, a redox coupling was verified when using $\mathrm{CaP} / \mathrm{MABA} / \mathrm{Cu}(\mathrm{II})$ electrode. In this case, it was observed that the average potential was $E_{m}=0.22 \mathrm{~V}$, therefore, the isotherm of copper(II) cation was investigated, which is $E_{m}=\left(E p_{c}+E p_{a}\right) / 2$, where $E p_{a}$ and $E p_{c}$ are cathodic and anodic peak potentials, respectively. In comparison with some results obtained, this wave can be attributed to the following electron transfer process [23]:

$$
\left[\mathrm{Cu}^{\mathrm{II}}(\mathrm{CaP} / \mathrm{MABA})_{4}\right]+s^{+}+e^{-} \rightleftharpoons\left[\mathrm{sCu}^{\mathrm{I}}(\mathrm{CaP} / \mathrm{MABA})_{4}\right],
$$

where in the redox process the supporting electrolyte $s^{+}$ must diffuse into or move out of the surface structured complex.

To verify the chemical stability of the copper(II) complex on calcium phosphate intercalated with $\mathrm{m}$ aminobenzoic acid, several scans were made in a potential range between $-1.0 \mathrm{~V}$ and $1.0 \mathrm{~V}$ versus SCE at a sweep speed $20 \mathrm{mVs}^{-1}$ with the modified electrode immersed in a $0.10 \mathrm{~mol} \mathrm{dm}^{-3}$ phosphate buffer solution. Results indicate that no significant variation was observed before 100 redox cycles (Figure 5). Peak current intensities remained practically constant, therefore the copper(II) complex is strongly adhered to the calcium phosphate intercalated with $\mathrm{m}$-aminobenzoic acid.

Cyclic voltammograms reached at different scan rates indicate that the value of $\Delta E_{p}\left(\Delta E_{p}=E_{p a}-E_{p c}\right)$ increases at higher ratios. Such result reflects that kinetics of electron

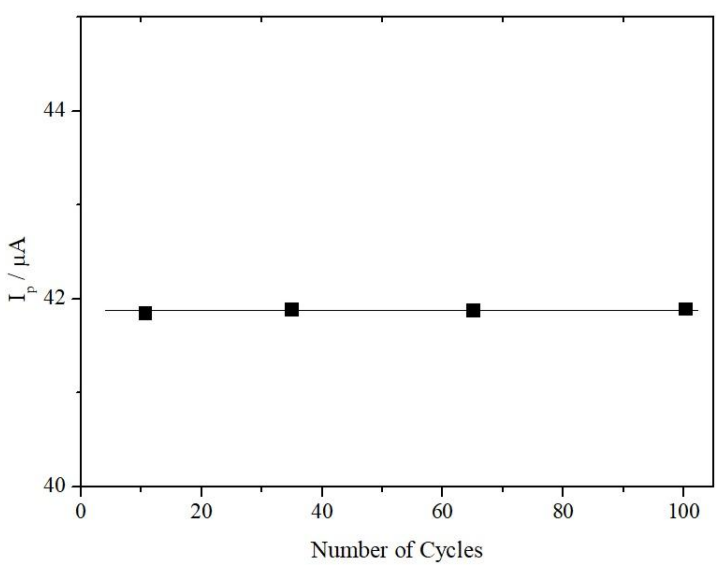

Figure 5: Plot of peak current, $I_{p}$ versus number of cycles, for a CaP/MABA/Cu(II) electrode in $0.10 \mathrm{~mol} \mathrm{dm}^{-3}$ phosphate buffer at $\mathrm{pH}$ 7.2.

transfer on the electrode surface is not enough fast, as a consequence of having a matrix with considerable resistance. The correlation of the peak current, $I_{p a}$ and $I_{p c}$, against $v^{1 / 2}$ ( $v$ is the scan rate) is linear, which is very similar to a diffusion controlled process [24]. Since the electroactive species strongly adheres to the matrix, as it was shown earlier, the mechanism may be explained by ion transport of the supporting electrolyte from electrode surface for charge compensation [25].

\subsection{Electrocatalytic oxidation}

DA oxidation on the $\mathrm{CaP} / \mathrm{MABA} / \mathrm{Cu}(\mathrm{II})$ electrode surface is shown in Figure 6. Cyclic voltammetric curves in presence of $1.3 \times 10^{-3} \mathrm{~mol} \mathrm{dm}^{-3}$ DA solution at $\mathrm{pH} 7.2$ show important enhancement of electrode anodic peak current. The cathodic peak permanence was associated with stronger interaction between the complex of copper present in electrode and matrix surface [26]. Another explanation of cathodic peak permanence was associated with DA oxidation products. This was verified by using glassy carbon electrode in presence of DA solution. Similar behavior was also checked in others systems [27]. DA electrochemical oxidation has been studied mostly on CPEs [28,29,30] and the complete effect matches to a two-electron process, followed by two-proton process, as shown in (5); the reaction denotes the oxidation of DA into DA $o$-quinone (DAQ) [31].

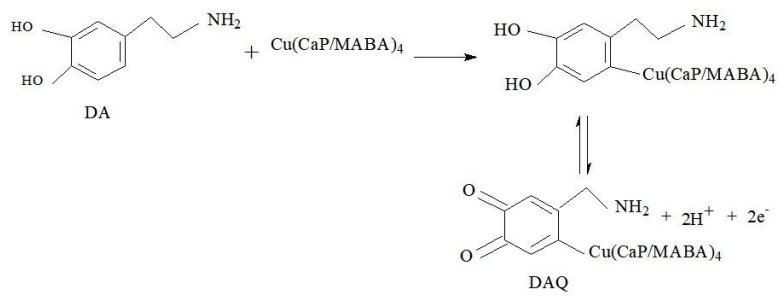




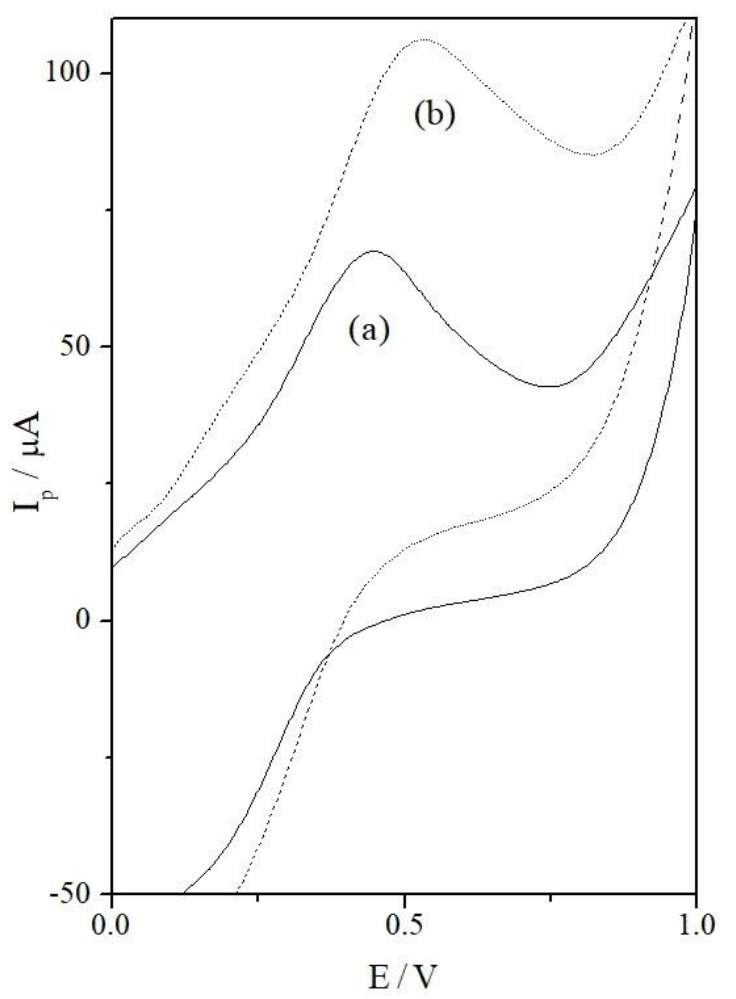

Figure 6: Cyclic voltammogram curves for the CaP/MABA/ $\mathrm{Cu}$ (II) electrode in the (a) absence and (b) presence of DA $\left(0.10 \mathrm{~mol} \mathrm{dm}^{-3}\right.$ phosphate buffer $)$ at $\mathrm{pH} 7.2$. Scan rate of $20 \mathrm{mVs}^{-1}$.

The effect of solution $\mathrm{pH}$ on the response of DA was explored (data not shown). Normally, the $\mathrm{pH}$ on response of DA must be taken into consideration [32]. In the present case, $\mathrm{CaP} / \mathrm{MABA} / \mathrm{Cu}(\mathrm{II})$ electrode was immersed in $[\mathrm{DA}]=2.0 \times 10^{-3} \mathrm{~mol} \mathrm{dm}^{-3}$ and $0.10 \mathrm{~mol} \mathrm{dm}^{-3}$ of phosphate buffer solution, and the $\mathrm{pH}$ was changed between 2.0 and 9.0. The current remained practically constant throughout interval, while at $\mathrm{pH}$ below 4.5, a considerable decrease in the response was detected. Therefore, the difference in the $\mathrm{pH}$ dependence of DA means that DA oxidation uses different proton and electron transfer mechanisms. According to Nernst equation, the slope of $-55.7 \mathrm{mV} / \mathrm{pH}$ unit reveals that the proportion of the electron and proton involved in the reactions is $1: 1$. As the DA oxidation is a two-electron process, the number of protons involved is also predicted to be two [33].

The plot of current peak against DA concentration is shown in Figure 7. A linear correlation with the concentration of the acid between $0.35 \times 10^{-3}$ and $1.60 \times 10^{-3} \mathrm{~mol} \mathrm{dm}^{-3}$ is observed with a detection limit of $0.35 \times 10^{-3} \mathrm{~mol} \mathrm{dm}^{-3}$. The proposed electrode presents a higher detection limit for DA which makes the sensor very attractive for determination of DA in drugs, in comparison with other modified electrodes $[34,35]$.

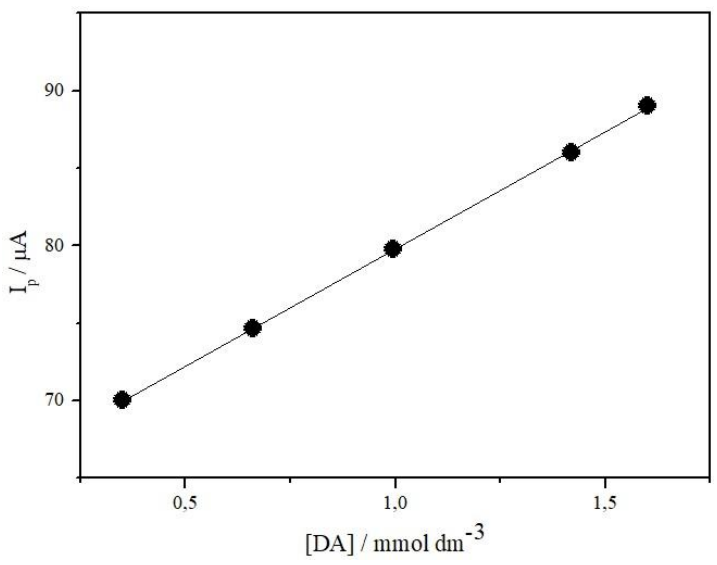

Figure 7: Plot of anodic peak current $\left(I_{p a}\right)$ against DA concentration in a $0.10 \mathrm{~mol} \mathrm{dm}^{-3}$ phosphate buffer solution at $\mathrm{pH}$ 7.2. Scan rate of $20 \mathrm{mVs}^{-1}$.

As stability indicator of the modified electrode towards DA, the electrode performance over 3 months period with measurements of the oxidation peak currents for $0.10 \mathrm{~mol} \mathrm{dm}^{-3}$ DA solution in $0.35 \mathrm{~mol} \mathrm{dm}^{-3}$ phosphate buffer solution ( $\mathrm{pH}$ 7.2) was observed each single day. The electrode was used daily and experimental results indicated that the current responses showed a relative standard deviation of $3.50 \%$, suggesting that the modified electrode possesses a good stability.

\subsection{Interference study}

Major sources of interference in DA determination can be of few common coexisting species in biological fluids which could lead to either new voltammetric peaks or an overlap with the existing ones, thereby influencing their voltammetric response [36]. Citric acid, tartaric acid, glucose, uric acid, $\mathrm{AA}$, and sodium chloride $(\mathrm{NaCl})$ effect on voltammetric peak response of $1.5 \times 10^{-3} \mathrm{~mol} \mathrm{dm}^{-3}$ of DA was examined. It was observed that 310 -fold concentrations of $\mathrm{NaCl}$, tartaric acid, and glucose; 105-fold concentration of citric acid; and 11-fold concentration of uric acid and AA have no significant influence on the voltammetric peak response of $2.0 \times 10^{-6} \mathrm{~mol} \mathrm{dm}^{-3} \mathrm{DA}$. The peak current signal change was below $4 \%$ in all the cases.

\subsection{Determination of DA in real samples}

The result achieved using cyclic voltammetry for a commercial sample with the $\mathrm{CaP} / \mathrm{MABA} / \mathrm{Cu}$ (II) electrode is $5.01 \pm 0.12 \mathrm{mg} \mathrm{cm}^{-3}$ and $5.02 \pm 0.18 \mathrm{mg} \mathrm{cm}^{-3}$, respectively, in good agreement with a confidence interval of $96 \%$ for $n=10$, with the label value of $5.0 \mathrm{mg} \mathrm{cm}^{-3}$, thus, indicating the electrode feasibility in DA determinations in real sample. Studies have shown that the electrode is stable under operating conditions. Results obtained with this electrode are excellent, considering that other 
chemical elements interfere with the results. Benefits of using this electrode are mainly the ease of its preparation and also the short response time spent on the analytical procedure. Reproducibility of the electrode was explored. Repetitive measurements were performed with DA. Results of 150 successive measurements showed a relative standard deviation of $1.03 \%$. Therefore, modified electrodes are very stable and great reproducibility is observed.

\section{Conclusions}

Calcium phosphate host intercalated with m-aminobenzoic acid was synthesized. Results obtained from the electrode containing copper(II) were very promising. The benefits of using proposed electrodes have been stated by our analytical procedures, and its development is simple. The electrode did not show important changes in response after three months use, thus presenting good chemical stability. These characteristics make this material very attractive to use as sensor for DA determination.

Acknowledgments The authors are indebted to Josué A. da Silva for manuscript revision.

Conflict of interest The authors declare that they have no conflict of interest.

\section{References}

[1] A. M. Lazarin and C. Airoldi, Layered crystalline barium phosphate organofunctionalized for cation removal, Chem Mater, 18 (2006), 2226-2232.

[2] M. G. Vieira, G. de Souza, G. H. B. Aristides, L. V. Lopes, and A. M. Lazarin, Construction of a new sensor with ruthenium complex anchored in functionalized silica and their application in determination of ascorbic acid in industrial fruit juice, Int $\mathbf{J}$ Sens Netw, 5 (2017), 27-33.

[3] B. B. Cazula and A. M. Lazarin, Development of chemically modified carbon paste electrodes with transition metal complexes anchored on silica gel, Mater Chem Phys, 186 (2017), 470-477.

[4] A. M. Lazarin, F. M. de Souza, S. Pelisson, B. B. Cazula, and S. C. F. Santos, Synthesis and characterization of EDTA organofunctionalization the surface of the silica SF-3APTS and its application as a complexing agent of copper(II), Acad J Appl Sci Res, 1 (2016), 1-6.

[5] M. H. Pournaghi-Azar and H. Razmi-Nerbin, Electrocatalytic characteristics of ascorbic acid oxidation at nickel plated aluminum electrodes modified with nickel pentacyanonitrosylferrate films, J Electroanal Chem, 488 (2000), 17-24.

[6] F. M. de Souza, B. Babeto, S. Pelisson, and A. M. Lazarin, Adsorption of cobalt (II) complex on a calcium phosphate intercalated with p-aminobenzoic acid synthesis, electrochemical properties and dopamine oxidation study, J Chem Eng Chem Res, 1 (2014), 67-76.

[7] C. R. Raj and T. Ohsaka, Electroanalysis of ascorbate and dopamine at a gold electrode modified with a positively charged self-assembled monolayer, J Electroanal Chem, 496 (2001), 4449.

[8] S. M. M. Romanowski and A. S. Mangrich, Synthesis and characterization of new copper (II) coordination compounds with unsymmetrical N,O-donor ligands: contributions for the galactose oxidase active site, Quim Nova, 24 (2001), 592-598.
[9] V. S. Ijeri, M. Algarra, and A. Martins, Electrocatalytic determination of vitamin $C$ using calixarene modified carbon paste electrodes, Electroanalysis, 16 (2004), 2082-2086.

[10] E. R. de Sousa, E. P. Marques, E. N. Fernandes, J. Zhang, and A. L. B. Marques, Graphite electrodes modified by 8hydroxyquinolines and its application for the determination of copper in trace levels, J Braz Chem Soc, 17 (2006), 177-183.

[11] T. Müller, Catechol-O-methyltransferase inhibitors in Parkinson's disease, Drugs, 75 (2015), 157-174.

[12] K. C. Schmitt, R. B. Rothman, and M. E. Reith, Nonclassical pharmacology of the dopamine transporter: atypical inhibitors, allosteric modulators, and partial substrates, J Pharmacol Exp Ther, 346 (2013), 2-10.

[13] S. López-Pérez, A. Morales-Villagrán, and L. Medina-Ceja, Effect of perinatal asphyxia and carbamazepine treatment on cortical dopamine and DOPAC levels, J Biomed Sci, 22 (2015), 14.

[14] P. Ramesh, G. S. Suresh, and S. Sampath, Selective determination of dopamine using unmodified, exfoliated graphite electrodes, $\mathrm{J}$ Electroanal Chem, 561 (2004), 173-180.

[15] A. P. dos Reis, C. R. Tarley, N. Maniasso, and L. T. Kubota, Exploiting micellar environment for simultaneous electrochemical determination of ascorbic acid and dopamine, Talanta, 67 (2005), 829-835.

[16] F. Alves, P. Smichowski, S. Farías, J. Marrero, and M. Arruda, Direct analysis of Antarctic krill by slurry sampling: determination of copper, iron, manganese and zinc by flame atomic absorption spectrometry, J Braz Chem Soc, 11 (2000), 365-370.

[17] O. İnel and F. Tümsek, The measurement of surface areas of some silicates by solution adsorption, Turk J Chem, 24 (2000), 9-19.

[18] A. M. Lazarin, T. A. Ganzerli, R. L. Sernaglia, E. I. S. Andreotti, and C. Airoldi, Calcium phenylphosphonate as a host for 4-aminobenzoic acid-Synthesis, characterization, and cation adsorption from ethanol solution, Mater Res Bull, 44 (2009), 2087-2091.

[19] O. G. Silva, M. G. da Fonseca, and L. N. H. Arakaki, Silylated calcium phosphates and their new behavior for copper retention from aqueous solution, Colloids Surf A Physicochem Eng Asp, 301 (2007), 376-381.

[20] L. V. A. Gurgel and L. F. Gil, Adsorption of $\mathrm{Cu}(\mathrm{II}), \mathrm{Cd}(\mathrm{II})$, and $P b(I I)$ from aqueous single metal solutions by succinylated mercerized cellulose modified with triethylenetetramine, Carbohydr Polym, 77 (2009), 142-149.

[21] M. G. Vieira and A. M. Lazarin, Adsorption of metallic ions in lamellar crystalline compounds intercalated with organic molecules, Am J Polym Sci Technol, 2 (2016), 47-53.

[22] C. Airoldi and S. Roca, Calorimetric study of intercalation of n-alkyldiamines into $\alpha$-titanium hydrogenphosphate, J Mater Chem, 6 (1996), 1963-1966.

[23] C. A. Borgo, R. T. Ferrari, L. M. S. Colpini, C. M. M. Costa, M. L. Baesso, and A. C. Bento, Voltammetric response of $a$ copper(II) complex incorporated in silica-modified carbon-paste electrode, Anal Chim Acta, 385 (1999), 103-109.

[24] L. B. Panice, E. A. de Oliveira, R. A. D. Molin Filho, D. P. de Oliveira, A. M. Lazarin, E. I. S. Andreotti, et al., Electrochemical properties of the hexacyanoferrate(II)-ruthenium(III) complex immobilized on silica gel surface chemically modified with zirconium(IV) oxide, Mater Sci Eng B, 188 (2014), 78-83.

[25] L. T. Kubota, Y. Gushikem, J. Perez, and A. A. Tanaka, Electrochemical properties of iron phthalocyanine immobilized on titanium(IV) oxide coated on silica gel surface, Langmuir, 11 (1995), 1009-1013.

[26] M. A. Kamyabi and M. A. Shafiee, Electrocatalytic oxidation of dopamine, ascorbic acid and uric acid at poly-2,6-diaminopyridine on the surface of carbon nanotubes/GC electrodes, J Braz Chem Soc, 23 (2012), 593-601. 
[27] N. Nasirizadeh, Z. Shekari, H. R. Zare, S. A. Y. Ardakani, and H. Ahmar, Developing a sensor for the simultaneous determination of dopamine, acetaminophen and tryptophan in pharmaceutical samples using a multi-walled carbon nanotube and oxadiazole modified glassy carbon electrode, J Braz Chem Soc, 24 (2013), 1846-1856.

[28] B. N. Chandrashekar, B. E. Kumara Swamy, M. Pandurangachar, S. Sharath Shankar, O. Gilbert, J. G. Manjunatha, et al., Electrochemical oxidation of dopamine at polyethylene glycol modified carbon paste electrode: A cyclic voltammetric study, Int J Electrochem Sci, 5 (2010), 578-592.

[29] M. Pandurangachar, B. E. Kumara Swamy, B. N. Chandrashekar, and B. S. Sherigara, Cyclic voltammetric investigation of dopamine at p-aminobenzoic acid modified carbon paste electrode, Int J Electrochem Sci, 4 (2009), 1319-1328.

[30] P. M. Santos, B. Sandrino, T. F. Moreira, K. Wohnrath, N. Nagata, and C. A. Pessoa, Simultaneous voltammetric determination of dopamine and ascorbic acid using multivariate calibration methodology performed on a carbon paste electrode modified by a mer-[RuCl $\left.{ }_{3}(d p p b)(4-p i c)\right]$ complex, J Braz Chem Soc, 18 (2007), 93-99.

[31] M. Aguilar-Martínez, N. Macías-Ruvalcaba, and I. González, Traveling through the square mechanism of the quinone reduction pathways. Influence of the proton donor addition on the reaction intermediaries in a non-aqueous solvent, Rev Soc Quim Mex, 44 (2000), 74-81.

[32] H. Razmi, M. Agazadeh, and B. Habibi, Electrocatalytic oxidation of dopamine at aluminum electrode modified with nickel pentacyanonitrosylferrate films, synthesized by electroless procedure, J Electroanal Chem, 547 (2003), 25-33.

[33] S. Zheng, Y. Huang, and G. Chen, Electrochemical behavior of o-sec-butylphenol at glassy carbon electrode modified with multiwalled carbon nanotubes and 1-butyl-3-methylimidazolium hexafluorophosphate, Analyst, 137 (2012), 4335-4342.

[34] I. Zablocka, M. Wysocka-Zolopa, and K. Winkler, Electrochemical detection of dopamine at a gold electrode modified with a polypyrrole-mesoporous silica molecular sieves (MCM-48) film, Int J Mol Sci, 20 (2019), 111.

[35] A. Babaei, M. Afrasiabi, S. Mirzakhani, and A. R. Taheri, A sensitive determination of acetaminophen in pharmaceutical preparations and biological samples using multi-walled carbon nanotube modified glassy carbon electrode, J Braz Chem Soc, 22 (2011), 344-351.

[36] A. M. Pisoschi, A. Pop, G. P. Negulescu, and A. Pisoschi, Determination of ascorbic acid content of some fruit juices and wine by voltammetry performed at Pt and carbon paste electrodes, Molecules, 16 (2011), 1349-1365. 